\title{
Estimativa do fluxo dos resíduos de equipamentos elétricos e eletrônicos no município de Belo Horizonte, Minas Gerais, Brasil
}

\author{
Flow of e-waste at the city of Belo Horizonte, Minas Gerais, Brazil
}

\author{
Rosana Gonçalves Ferreira Franco \\ Química. Mestre em Saneamento, Meio Ambiente e Recursos Hídricos pelo Departamento de Engenharia Sanitária e Ambiental da \\ Universidade Federal de Minas Gerais (UFMG)
}

\section{Liséte Celina Lange}

Química. Doutora em Tecnologia Ambiental pela Universidade de Londres. Professora Associada do Departamento de Engenharia Sanitária e Ambiental da UFMG

\section{Resumo}

O objetivo deste trabalho foi determinar o fluxo dos resíduos de equipamentos elétricos e eletrônicos (REEE) no município de Belo Horizonte - Minas Gerais, Brasil. Para atingir o objetivo, pesquisaram-se a estimativa de geração, a quantidade e o peso dos materiais recicláveis e de substâncias tóxicas presentes Os resultados mostraram que o potencial de geração é de 153 mil toneladas de resíduos para o período de 2008 a 2023, e a principal destinação dada pelos consumidores particulares para o descarte desses resíduos é a doação. Concluiu-se que as iniciativas de gerenciamento ambientalmente adequadas são oriundas de iniciativas privadas e aplicadas somente em equipamentos de informática e telefonia móvel, e que os demais resíduos estão sendo manipulados sem as devidas precauções de saúde e segurança do trabalhador, bem como dispostos de forma irregular.

Palavras-chave: resíduos de equipamentos eletroeletrônicos (REEE); fluxo de geração de resíduos eletroeletrônicos; gerenciamento de resíduos sólidos, reciclagem

\section{Abstract}

The aim of this study was to obtain an understanding of the flow of e-waste at the city of Belo Horizonte - Minas Gerais, Brazil. An estimative of the amount of e-waste generated and the domestic and second hand flow were investigated to achieve this goal. The results estimated approximately 153,000 tones of e-waste generated for the period of 2008 to 2023 , and the main domestic disposal given by the consumers is donation. We concluded that the environmental management initiatives usually comes from the private sector and are applied to computers and mobile phones only. Other e-wastes are handled using improper tools, creating health and safety hazards for the workers, as well as those e-wastes have been arranged in an irregular way.

Keywords: waste electrical and electronic equipment (WEEE), flow of e-waste; solid waste management, recycling. 


\section{Introdução}

Os resíduos de equipamentos elétricos e eletrônicos (REEE) estão em processo de plena expansão, inclusive nos países em desenvolvimento. A redução dos preços de venda, a crescente inovação tecnológica e a diminuição do tempo de vida útil são alguns dos fatores que contribuem para o seu descarte. A preocupação quanto aos impactos ambientais desses resíduos se justifica pelo fato de que muitos dos REEE são descartados indevidamente. Alguns países em desenvolvimento na África e Ásia, como relatado na literatura, importam REEE com o propósito de reutilizar equipamentos (exemplo: computadores que farão parte de programas de inclusão digital) ou aproveitar partes do equipamento devido ao valor econômico dos materiais envolvidos. Embora alguns dos equipamentos importados possam de fato ser utilizados segundo sua função de origem, outros são desmontados indevidamente causando sérios problemas ambientais (LIU; TANAKA; MATSUI, 2006).

No Brasil há estudos que apontam para esse manuseio indevido em muitas associações de catadores de recicláveis, onde os trabalhadores, por não saberem do potencial tóxico de muitos materiais, recuperam os metais de forma artesanal (FRANCO, 2008).

Entre os componentes dos dispositivos eletrônicos existem substâncias e materiais tóxicos como chumbo, cádmio, mercúrio, bifenilas policloradas (PCBs) e éter difenil polibromado (PBDE), entre outros, assim como materiais que, ao serem incinerados em condições inadequadas, são percussores na formação de outras substâncias tóxicas como as dioxinas e os furanos (ROMAN, 2007). Vários estudos em áreas onde se faz a recuperação desses materiais de maneira inadequada têm sido realizados. Estudos que envolvem análise de sedimentos, solos, material particulado, presença de contaminantes em cabelo e leite humano (WANG et al., 2009; XING et al., 2009; LIM; SCHOENUG, 2010).

Nos países desenvolvidos este tema tem sido vastamente estudado, com a existência de regulamentações que incluem a responsabilidade do produtor sobre o gerenciamento dos seus produtos pós-consumo, assim como legislações sobre a restrição de uso de substâncias tóxicas na fabricação dos equipamentos eletrônicos. No Brasil ainda são escassas as pesquisas sobre o tema, principalmente no que diz respeito à gestão adequada para esses resíduos. Estudos apresentados por Rodrigues (2007) sobre o potencial de geração de REEE no Brasil para 2002 a 2016 mostraram média anual de geração que corresponde a 493.400 toneladas, representando esse total a média per capita de $2,6 \mathrm{~kg} / \mathrm{ano}$.

Sob a ótica legal, tem-se um avanço com a nova Lei dos Resíduos Sólidos - 12.305/2010 (BRASIL, 2010) sancionada em agosto de 2010 e ainda a ser regulamentada. A lei aponta os REEE como resíduos em que após o uso pelo consumidor, de forma independente do serviço público de limpeza urbana e de manejo dos resíduos sólidos, os fabricantes, importadores, distribuidores e comerciantes serão obrigados a estruturar e implementar sistemas de logística reversa, mediante retorno dos produtos.

Em Belo Horizonte, Franco (2008) estimou uma geração de resíduos de 152.841 toneladas entre os anos de 2010 e 2023, somente entre aparelhos de refrigeração, televisores, computadores pessoais e telefones celulares, o que leva a pensar em uma quantidade maior de geração de resíduos. Números esses subestimados, uma vez que dados sobre produção, venda e tempo de vida útil dos equipamentos são limitados.

Esse número expressivo de posse de bens de consumo duráveis induziu a questionar o destino dado a esses produtos quando não são mais úteis a seus possuidores - pós-consumo, além de como esses resíduos estavam sendo gerenciados e por que esses resíduos necessitam de uma gestão especial. Dessa forma, o presente trabalho objetivou obter um diagnóstico do fluxo dos REEE do município de Belo Horizonte, Minas Gerais.

\section{Material e método}

A metodologia aplicada no desenvolvimento da presente pesquisa subdividiu-se em duas fases, ou seja, estimar a geração de REEE, a quantidade e o peso dos materiais recicláveis e de substâncias tóxicas presentes em diferentes equipamentos e diagnosticar o fluxo dos REEEs do município de Belo Horizonte.

Antes do início da fase 2 da pesquisa, o projeto inicial foi submetido ao Comitê de Ética em Pesquisa da Universidade Federal de Minas Gerais (COEP/UFMG), sendo aprovado em julho de 2008 sob o número de registro CAAE - 0261.0.203.000-8. Após a aprovação, iniciou-se a coleta de dados.

$\mathrm{Na}$ primeira fase, foram usados os dados obtidos por meio da Pesquisa Nacional por Amostra de Domicílio (IBGE, 2006) para os refrigeradores e congeladores, aparelhos de televisão e computadores. Para os telefones celulares, foram adotados os dados fornecidos pelo Relatório da Agência Nacional de Telecomunicações - Acessos/ Plano de Serviço/Unidade de Federação (ANATEL, 2011).

$\mathrm{Na}$ segunda fase, primeiramente, delimitou-se a área de estudo; posteriormente, identificaram-se os atores envolvidos na cadeia pósconsumo desses equipamentos, que foram submetidos a entrevistas e/ou aplicação de questionários. Os dados foram analisados, determinando-se, assim, o fluxo dos REEEs no município.

\section{Fase 1: Estimativa da geração de resíduos de equipamentos elétricos e eletrônicos domésticos}

Segundo a Diretiva 2002/95/CE (PARLAMENTO EUROPEU, 2003) são definidas dez categorias para os equipamentos eletroeletrônicos (EEE) que vão desde os pequenos eletrodomésticos até os distribuidores automáticos. Como as categorias de EEE são abrangentes, para esta pesquisa foram adotadas unidades de estudo segundo a Tabela 1. 
A seleção desses equipamentos deu-se de acordo com os seguintes critérios:

- equipamentos para os quais existem dados disponíveis de domicílios brasileiros;

- equipamentos com crescentes volumes de vendas nos últimos anos;

- equipamentos que são rapidamente substituídos por outros de novas tecnologias;

- equipamentos que apresentam potencial tóxico quando descartados indevidamente;

Por falta de dados nacionais sobre a vida útil média dos equipamentos elétricos e eletrônicos, adotaram-se como padrão os prazos estabelecidos no estudo realizado pela Agência de Proteção Ambiental dos Estados Unidos (US-EPA, 2007), sendo: refrigerador e freezer - 15 anos; computadores pessoais - 5 anos; telefones celulares - 2 anos; e aparelhos de televisão - 13 anos.

\section{Fase 2: Diagnóstico do fluxo de REEEs domésticos no município de $\mathrm{BH}$}

O município de Belo Horizonte está situado no Centro-Sul do Estado de Minas Gerais, com extensão territorial de 335 km² e população de 2.412.937 habitantes. A qualidade de vida de sua população, se vista pelo índicie de desenvolvimento humano (IDH), 0,839, é acima da média brasileira $(0,775)$ - (BRASIL, 2000), o que se traduz no desenvolvimento de um mercado de consumo com elevado potencial de geração de resíduo.

O acelerado e desordenado crescimento levou a Prefeitura Municipal de Belo Horizonte a criar nove administrações regionais no município. Por possuírem perfil econômico diferenciado, as regionais podem apresentar potencial de geração de REEE também diferente. Esta pesquisa não identificou a geração por região, porém recomenda uma análise mais detalhada para implementação dos pontos de coleta.

Após delimitar a área de estudo foram identificados os atores envolvidos na cadeia pós-consumo desses equipamentos, sendo: consumidores particulares; empresas que comercializam materiais recicláveis; cooperativas de catadores de materiais recicláveis; organizações assistenciais que trabalham com inclusão digital; empresas de triagem e descaracterização; locais de disposição final e órgãos gestores municipais, estaduais e federais.

Para amostragem dos 'consumidores particulares', optou-se por amostras não probabilísticas, que são selecionadas por critérios subjetivos do pesquisador, de acordo com sua experiência e com os objetivos do estudo, não sendo obtidas a partir de conceitos estatísticos (SAMARA; BARROS, 2002).

Para amostragem 'das empresas' que comercializam materiais recicláveis (sucateiros), delimitaram-se as localizadas no município de
Tabela 1 - Equipamentos selecionados para estudo

\begin{tabular}{lll} 
Categorias & $\begin{array}{l}\text { Equipamentos } \\
\text { selecionados }\end{array}$ & Substâncias perigosas \\
$\begin{array}{l}\text { Grandes } \\
\text { Eletrodomésticos }\end{array}$ & $\begin{array}{l}\text { Refrigerador e } \\
\text { congeladores }\end{array}$ & CFCs \\
$\begin{array}{l}\text { Equipamentos de } \\
\text { informática e de } \\
\text { telecomunicações }\end{array}$ & $\begin{array}{l}\text { Computadores e } \\
\text { telefones celulares }\end{array}$ & $\begin{array}{l}\mathrm{Pb}, \mathrm{PbO}, \mathrm{Hg}, \mathrm{Cd}, \mathrm{PCB}, \\
\mathrm{PVC}, \mathrm{retardantes} \mathrm{de} \\
\text { chama }\end{array}$ \\
$\begin{array}{l}\text { Equipamentos de } \\
\text { consumo }\end{array}$ & Aparelhos de televisão & $\begin{array}{l}\mathrm{Pb}, \mathrm{PbO}, \mathrm{Cd}, \mathrm{PCB}, \\
\mathrm{PVC}, \mathrm{retardantes} \mathrm{de} \\
\text { chama }\end{array}$ \\
\hline
\end{tabular}

Belo Horizonte cadastradas no website do Compromisso Empresarial para Reciclagem (CEMPRE). Em outubro de 2008 estavam cadastradas quatro empresas que comercializam sucatas de metal e uma empresa de sucata de resíduos eletrônicos. Para diagnosticar os procedimentos adotados na gestão dos resíduos nesse segmento, optou-se por visita ao local e entrevistas com os responsáveis pelo empreendimento.

Para o diagnóstico da gestão dos REEEs nas cooperativas de catadores de materiais recicláveis, foram feitas visitas com entrevistas aos responsáveis, nas sete cooperativas cadastradas no Fórum Municipal Lixo e Cidadania.

Para melhor caracterização do ciclo de vida pós-consumo dos computadores, necessitou-se entrevistar as 'organizações que trabalham com inclusão digital' e, para isso, identificaram-se no município tais instituições: Programa de Desenvolvimento de Informática, Informação e Dados do Município de Belo Horizonte (Prodabel), responsável pelo projeto do Centro de Recondicionamento de Computadores; e o Comitê para Democratização da Informática (CDI).

As 'empresas de triagem e descaracterização' de REEE foram obtidas no website do Cempre, onde estavam cadastradas, em junho de 2008, nove empresas no setor de reciclagem de eletrônicos. O contato foi feito via email ou telefone, ocasião em que o pesquisador solicitou uma visita; das nove empresas contatadas, apenas duas permitiram a visita do pesquisador, definindo-se, assim, a amostragem. Todas as empresas estão localizadas no estado de São Paulo. Em Minas Gerais, depois de exaustiva pesquisa em diversas fontes, não foi encontrada nenhuma empresa que oferecia esse serviço.

Para identificar o fluxo dos REEEs em 'locais de disposição final', visitou-se a Central de Tratamento de Resíduos Sólidos da BR-040, único local na época do estudo de disposição final dos resíduos sólidos do município de Belo Horizonte.

Os órgãos gestores foram escolhidos por estarem relacionados diretamente com a gestão de resíduos sólidos do município de Belo Horizonte e/ou do Estado de Minas Gerais, a seguir: Fundação Estadual de Meio Ambiente (Feam), Secretaria de Estado de Meio Ambiente e Desenvolvimento Sustentável (Semad), Centro Mineiro de Referência em Resíduos (CMRR) e Superintendência de Limpeza Urbana de Belo Horizonte (SLU). 


\section{Resultados}

\section{Fase 1: Quantidade estimada de resíduos de equipamentos elétricos e eletrônicos}

A Tabela 2 apresenta os resultados da estimativa de geração de REEE no município de Belo Horizonte.

O peso médio dos equipamentos eletrônicos foram determinados por meio de pesquisa nas fichas técnicas de seis produtos, disponíveis nos sites dos fabricantes, sendo telefones celulares: 0,1kg; computadores (CPU e tela): $22 \mathrm{~kg}$; refrigeradores: $53 \mathrm{~kg}$ e televisores de tecnologia CRT: $36 \mathrm{~kg}$.

Para obtenção do potencial de REEEs gerados, multiplicou-se o peso médio por aparelho pelo número de aparelhos estimados pelo IBGE nos domicílios particulares. Como os dados disponibilizados são referentes ao número de domicílios particulares que possuem tais equipamentos, no ano de 2006, e não fornece o ano de compra desses equipamentos, considerando-se a vida útil pode-se estimar um passivo ambiental no município de Belo Horizonte de:

- refrigeradores e congeladores - 87.980 t até o ano de 2023;

- televisores - 54.000 t até o ano de 2021;

- computadores - 10.560 t até o ano de 2013;

- telefones celulares - 301 t até o ano de 2012;

Considerando que a vida útil de um aparelho de refrigeração (congelador + refrigerador) é de aproximadamente 15 anos, podese considerar que até o ano de 2023 haverá, somente na cidade de Belo Horizonte, aproximadamente 1,66 milhão de aparelhos a serem descartados. Isto implicará, como demonstrado na Tabela 2, o total de 87.980 t de resíduos de equipamentos de refrigeração, o que corresponderia a 58.835 t de metal, 56.835 t, 537 t de CFC-11 e 12, conforme demonstrado na Tabela 3. Vale ressaltar que os hidroclorofluorcarbonos (HCFCs) não foram computados, pois somente na $19^{a}$ Reunião entre as partes do Protocolo de Montreal, ocorrido em setembro de 2007, foi acordada a Decisão XIX/6, que antecipa as datas para eliminação dessas substâncias, até então permitidas.

Segundo o IBGE (2006), Belo Horizonte possui 1,5 milhões de domicílios com pelo menos um aparelho de televisão. Considerando o peso médio de um aparelho de $36 \mathrm{~kg}$ e vida útil de 13 anos, existirá, até o ano de 2021, um passivo ambiental de aproximadamente $54.000 \mathrm{t}$ de materiais, como demonstrado na Tabela 4.

Segundo o IBGE (2006), Belo Horizonte possui 0,48 milhão de domicílios com pelo menos 1 computador pessoal. Considerando o peso médio de um aparelho de $22 \mathrm{~kg}$ e vida útil de 5 anos até o ano de 2013 haverá um passivo ambiental de aproximadamente $10.560 \mathrm{t}$ de materiais, como demonstrado na Tabela 5.

Destaca-se que não foram considerados para cálculo os computadores pessoais de uso nas empresas, pois esses dados são contabilizados, atualmente, pela Fundação Getulio Vargas, Escola de Administração de Empresas de São Paulo (FGV/Eaesp) somente em nível nacional. Segundo estimativa da FGV/Eaesp (2007) para os anos de 2009/2010, o Brasil terá, aproximadamente, 60 milhões de computadores de uso doméstico e empresarial.

\section{Fase 2: Situação do fluxo dos REEEs no município de Belo Horizonte}

Não se pretendeu, com este levantamento, fazer uma análise representativa, mas, sim, indicar de forma ilustrativa alguns comportamentos dos 'consumidores particulares' em relação ao descarte de alguns de seus aparelhos eletrônicos. Para tanto, foi aplicado um questionário com o objetivo de conhecer os procedimentos adotados por tais consumidores quanto ao tempo que os eles levam para trocar esses aparelhos, período este denominado vida útil, bem como ao destino dado aos EEEs estudados após o descarte. Obteve-se o retorno positivo de 90 respondentes de um total de 150 questionários.

O perfil dos respondentes é de $52 \%$ que moram em apartamentos, $47 \%$ possuem lares constituídos até 20 anos e 59\% estão compreendidos na faixa salarial entre $\mathrm{R} \$ 412,00$ e 6.180,00. Tal levantamento caracteriza um grupo com potencial para troca de equipamentos eletrônicos devido à faixa salarial e ao tempo de constituição do lar. Foi questionado ainda com que frequência os consumidores particulares trocam os aparelhos de telefonia celular, computadores pessoais, refrigeradores e televisores.

Os dados revelaram período de troca superior a dois anos para a maioria dos respondentes, sendo 53\% a incidência no caso do telefone celular e 57\% para os computadores. Já em relação às geladeiras, os

Tabela 2 - Geração dos REEEs em Belo Horizonte, MG

\begin{tabular}{|c|c|c|c|c|c|c|}
\hline Equipamentos & Vida útil (anos) & Peso médio ${ }^{1}(\mathrm{~kg})$ & $\begin{array}{l}\text { Número de } \\
\text { aparelhos milhões) }\end{array}$ & $\begin{array}{c}\text { Relação de } \\
\text { domicílios² (\%) }^{2} \text { ( }\end{array}$ & $\begin{array}{l}\text { REEEs gerados } \\
\text { (toneladas) }\end{array}$ & Ano provável FVU \\
\hline Refrigerador & \multirow{2}{*}{15} & \multirow{2}{*}{53} & $1,44^{3}$ & 97 & \multirow{2}{*}{87.980} & \multirow{2}{*}{2023} \\
\hline Frezeer & & & $0,22^{3}$ & 14 & & \\
\hline Televisores & 13 & 25 & $1,5^{3}$ & 97 & 37.500 & 2021 \\
\hline Computadores & 5 & 22 & $0,48^{3}$ & 32 & 10.560 & 2013 \\
\hline Telefones celulares ${ }^{4}$ & 2 & 0,1 & $3,01^{4}$ & & 301 & 2012 \\
\hline
\end{tabular}

${ }^{1}$ média dos pesos calculada a partir de pesquisa das fichas técnicas dos produtos; ${ }^{2}$ em relação ao total de domicílios, 1,490 milhões; ${ }^{3}$ Fonte: IBGE (2006); ${ }^{4}$ Fonte: ANATEL (2011). 
resultados indicaram que $51 \%$ dos entrevistados trocam de aparelho em um período de até 15 anos e 23\% acima de 15 anos. Quanto aos televisores, para 69\% dos respondentes, a vida útil desses aparelhos situa-se no período de até 15 anos, sendo somente para 8\% acima de 15 anos.

Esses resultados mostraram-se compatíveis com os padrões de vida útil da EPA, adotados nesta pesquisa para o cálculo da estimativa de geração de REEE, sendo dois anos para celulares, cinco anos para computadores, 15 anos para refrigeradores e 13 anos para televisores.

A Figura 1 apresenta os dados obtidos na pesquisa sobre os procedimentos adotados pelos consumidores particulares quanto ao destino dado aos aparelhos de telefonia celular, computadores pessoais, refrigeradores e televisores ao final da vida útil.

Verificou-se que o destino mais utilizado pelos entrevistados para descartar seu aparelho de celular, TV, PC e geladeira após o final da primeira vida útil é a doação (34, 44, 36 e 48\%, respectivamente). A doação não implica o reúso do aparelho pela outra parte, pois suas condições de uso não foram consideradas na entrevista. Essa atitude pode ser avaliada como uma forma de o consumidor se desfazer do equipamento de maneira adequada, transferindo, assim, o problema de descarte para outro.

O hábito de guardar foi percebido para televisores (24\%) e celulares (23\%), provavelmente porque os aparelhos de celular são de pequeno porte, ocupando pouco espaço e os televisores devido ao hábito de se colocar os aparelhos antigos em outras dependências da residência. Essa afirmativa pode ser comprovada com a pergunta sobre quantos aparelhos de televisão em uso o entrevistado possuía em sua residência. Os resultados demonstram que 10\% dos entrevistados possuem apenas um aparelho de televisão em casa, 33\% dois aparelhos e $25 \%$ três aparelhos, o que leva a concluir que os valores adotados pela pesquisa estão subestimados. Adotaram-se como parâmetro para cálculo de quantidade de materiais os dados fornecidos pelo IBGE (2006), sendo apenas mensurado se o domicílio tem ou não aparelho de televisão e não a quantidade de aparelhos por residência.

O "mercado de sucatas" no município de Belo Horizonte ocorre de modo formal e informal. Em um dos comércios de sucata visitado foi relatado que os resíduos mais recebidos são placas de computadores, reatores, motores elétricos, computadores inteiros, máquinas de lavar roupa, tanques elétricos, geladeira e televisão. Quando questionados sobre a procedência desse material foi informado que são recebidos de empresas, catadores, consumidores particulares e leilões, que recebem, em média, $\mathrm{R} \$ 0,10$ por quilo de sucata.

O responsável informou que quando esse material chega ao depósito, é feita a seleção, isto é, são desmontados e separados por tipo de material, exemplo: no computador são separados o plástico, o material ferroso e a placa; na geladeira, o plástico, o alumínio e o motor, que é vendido para recondicionamento ou para separar o óleo e o cobre. Quando questionado sobre o "gás da geladeira", relatou que esta já chega sem o gás e que o material que não consegue ser comercializado, como os plásticos dos monitores, é descartado junto ao resíduo comum.
Tabela 3 - Peso dos materiais presentes nos resíduos de aparelhos de refrigeração

\begin{tabular}{lcc|} 
Material & \% em peso & Total em toneladas $^{2}$ \\
\hline Metal & 64,6 & 56.835 \\
\hline Plástico & 30,5 & 26.834 \\
\hline Vidro & 4,04 & 3.555 \\
Óleo & 0,19 & 168 \\
CFC-11 & 0,4 & 352 \\
CFC-12 & 0,21 & 185 \\
Mercúrio & 0,001 & 1 \\
\hline Total & 99,941 & 87.930
\end{tabular}

${ }^{1}$ Fonte: US-EPA (2007); ${ }^{2}$ Fonte: dados da pesquisa.

Tabela 4 - Peso dos materiais presentes nos resíduos de aparelhos de televisão

\begin{tabular}{lcc|}
\hline Materiais & \% em peso & Total em toneladas $^{2}$ \\
\hline Vidro & 54,8 & 29.592 \\
\hline Plásticos & 30,4 & 16.416 \\
\hline $\begin{array}{l}\text { Metais não ferrosos } \\
\text { (cobre e alumínio) }\end{array}$ & 3,0 & 1.620 \\
\hline Metais ferrosos & 7,0 & 3.780 \\
\hline Chumbo & 4,7 & 2.538 \\
\hline Total & 100 & 53.946
\end{tabular}

${ }^{1}$ Fonte: RIS (2003).

${ }^{2}$ Fonte: dados da pesquisa.

Tabela 5 - Peso dos materiais presentes nos resíduos de computadores pessoais

\begin{tabular}{lcc} 
Materiais & \% em peso & Total em $^{1}$ \\
Vidro & 24,8 & 2.619 \\
Plásticos & 23 & 2.429 \\
\hline Placa circuito impresso & \\
\hline Metais preciosos & $\star \star$ & $\star \star$ \\
Ferro & 0,02 & 2 \\
Chumbo & 20,47 & 2.162 \\
Alumínio & 6,3 & 665 \\
Cobre & 14,17 & 1.496 \\
Outros & 6,93 & 732 \\
Total & 4,3 & 454 \\
\hline
\end{tabular}

${ }^{1}$ Fonte: Kang e Schoenung (2005).

${ }^{2}$ Fonte: dados da pesquisa.

** Desmembrado em plásticos, metais e outras partes

Em outro depósito visitado, foi informado são recebidos todos os tipos de resíduos eletrônicos. Os procedimentos de descaracterização são os mesmos do anterior, ou seja, desmontam o aparelho para retirada do material de valor comercial e o restante é depositado junto aos resíduos sólidos urbanos. Neste, quando questionado sobre o "gás das geladeiras", foi informado que no processo de desmontagem corta-se o tubinho ao separar as peças e para o gás não vazar, lacra-se a saída, sendo os materiais vendidos para empresas de reciclagem.

Os relatos das entrevistas e os registros fotográficos revelaram que mesmo as empresas que trabalham com o mercado formal de sucatas estão despreparadas para a gestão adequada desses equipamentos, 


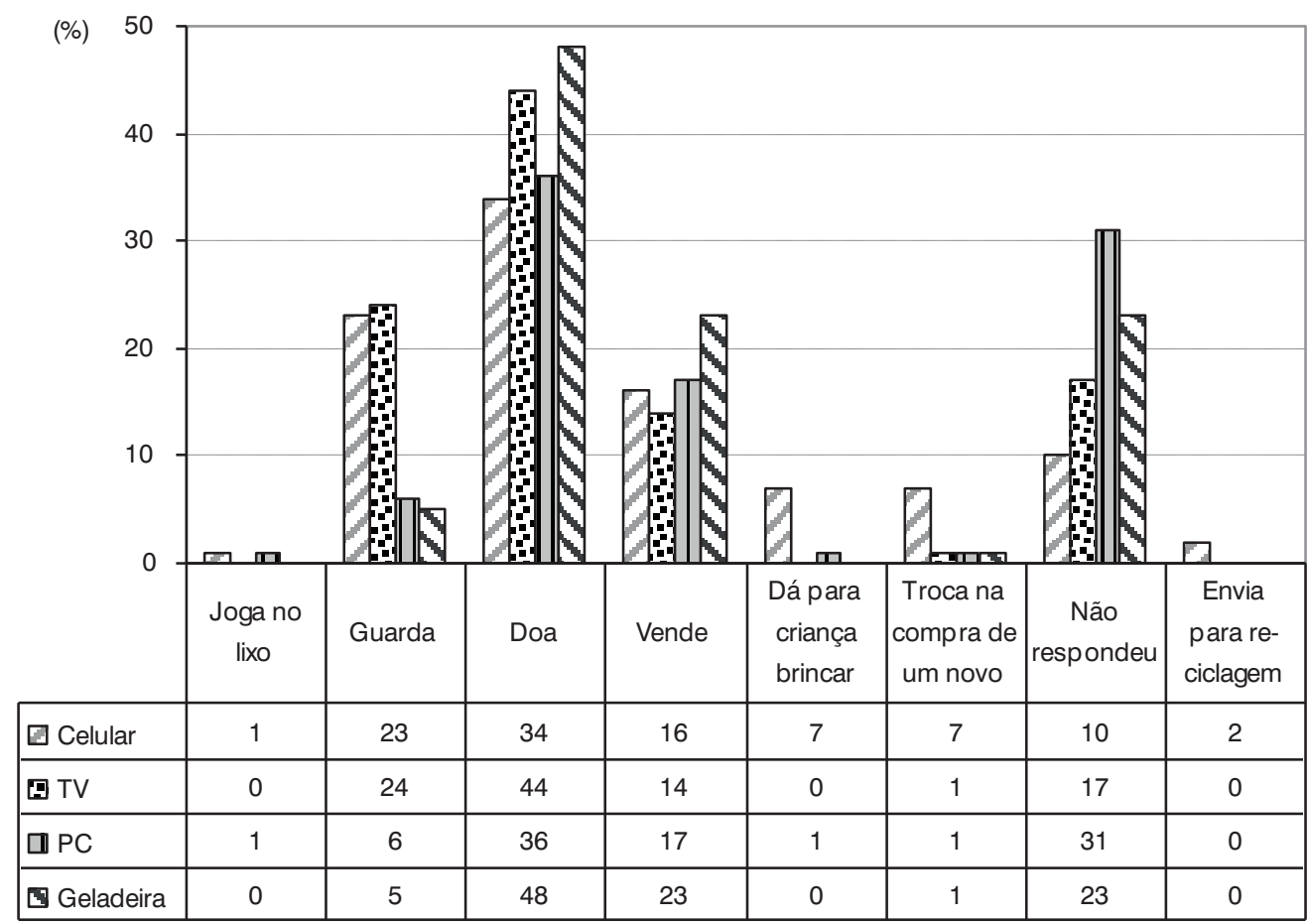

Fonte: dados da pesquisa.

Figura 1 - Destino dado aos aparelhos eletrodomésticos ao final da primeira vida útil.

desconhecendo o potencial tóxico de algumas peças e descartando o material sem valor comercial junto com os resíduos sólidos domiciliares. As Figuras 2 e 3 ilustram algumas das situações vivenciadas na pesquisa.

As sete cooperativas informaram que recebem todo tipo de equipamento eletrônico e que a quantidade recebida é muito variável. No entanto, notaram-se dificuldades dos entrevistados quanto ao conhecimento do que é considerado um REEE, uma vez que foi necessário citar exemplos de aparelhos eletrônicos para o entrevistado posicionar-se.

Constatou-se que esses materiais chegam às cooperativas por meio de doações de empresas, muitas vezes sem identificação, por catadores de porta a porta; pela coleta seletiva do município; e por doações de particulares diretamente às cooperativas.

Quando questionados sobre o que fazem com o material, houve certa padronização nos relatos, sendo o seguinte procedimento adotado: verifica-se se estão funcionando ou não, caso estejam são doados para os cooperativados ou usados na própria cooperativa, como no caso de geladeiras, fogões e computadores. Quando não estão funcionando, são desmontados e as peças separadas conforme o tipo de material. O plástico é vendido para as empresas denominadas por eles de "plastiqueiros" e o resíduo de metal vendido como sucata de ferro. O cobre e o alumínio são vendidos separadamente, devido ao alto valor comercial.
As placas de circuito impresso são revendidas para as pessoas que procuram diretamente esse tipo de material. Um dos entrevistados ressaltou que vende a $R \$ 8,00$ o quilo para uma empresa em Belo Horizonte e esta repassa para São Paulo pelo dobro do preço. Salientou que sabe que está vendendo o material abaixo do preço de mercado, manifestando conhecimento sobre a existência de metal precioso contido nesse tipo de sucata.

Um dos entrevistados relatou que, para retirar o cobre contido no tubo de raio catódico, ele coloca o tubo dentro de um saco plástico, envolto em um saco de pano e coberto com uma lona, quebra o vidro e espera "baixar a poeira, pois faz mal para saúde". Em seguida, tira o cobre para vender e coloca o caco de vidro no recipiente de reciclagem de vidro da SLU. Relatou também que usa equipamentos de segurança como óculos e luvas para proteção. Notou-se certo conhecimento do teor tóxico, porém, ao colocar o vidro para reciclagem, não há preocupação com a contaminação do restante do material contido no recipiente.

Identificou-se, com as entrevistas e visitas às cooperativas, total desconhecimento de como manipular esses resíduos e da responsabilidade em recebê-los. As empresas "doam" esse material para as cooperativas, repassando um passivo ambiental sem qualquer responsabilidade. A desmontagem para retirada do material de valor comercial é feita de forma precária, e as pessoas que manipulam desconhecem o potencial tóxico de algumas peças. 


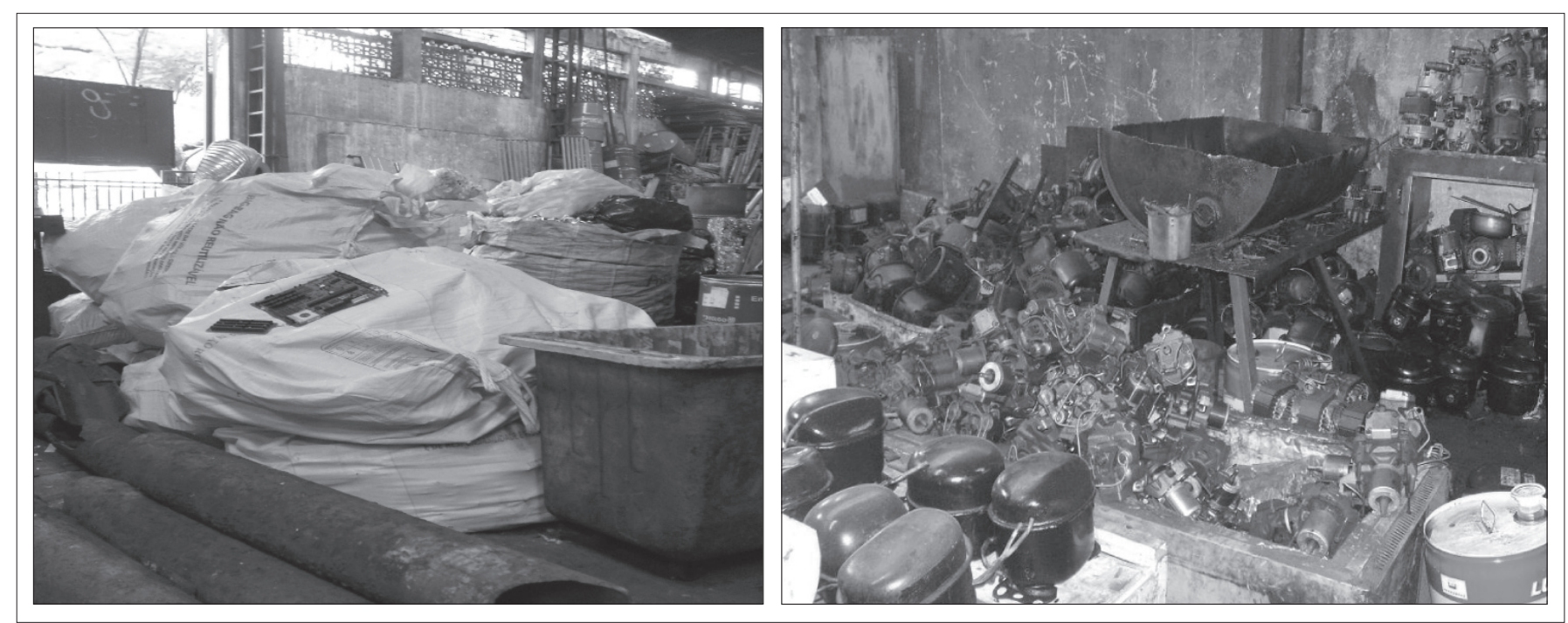

Figura 2 - Placas de circuito impresso embaladas para comercialização e motores elétricos desmontados em sucateiros
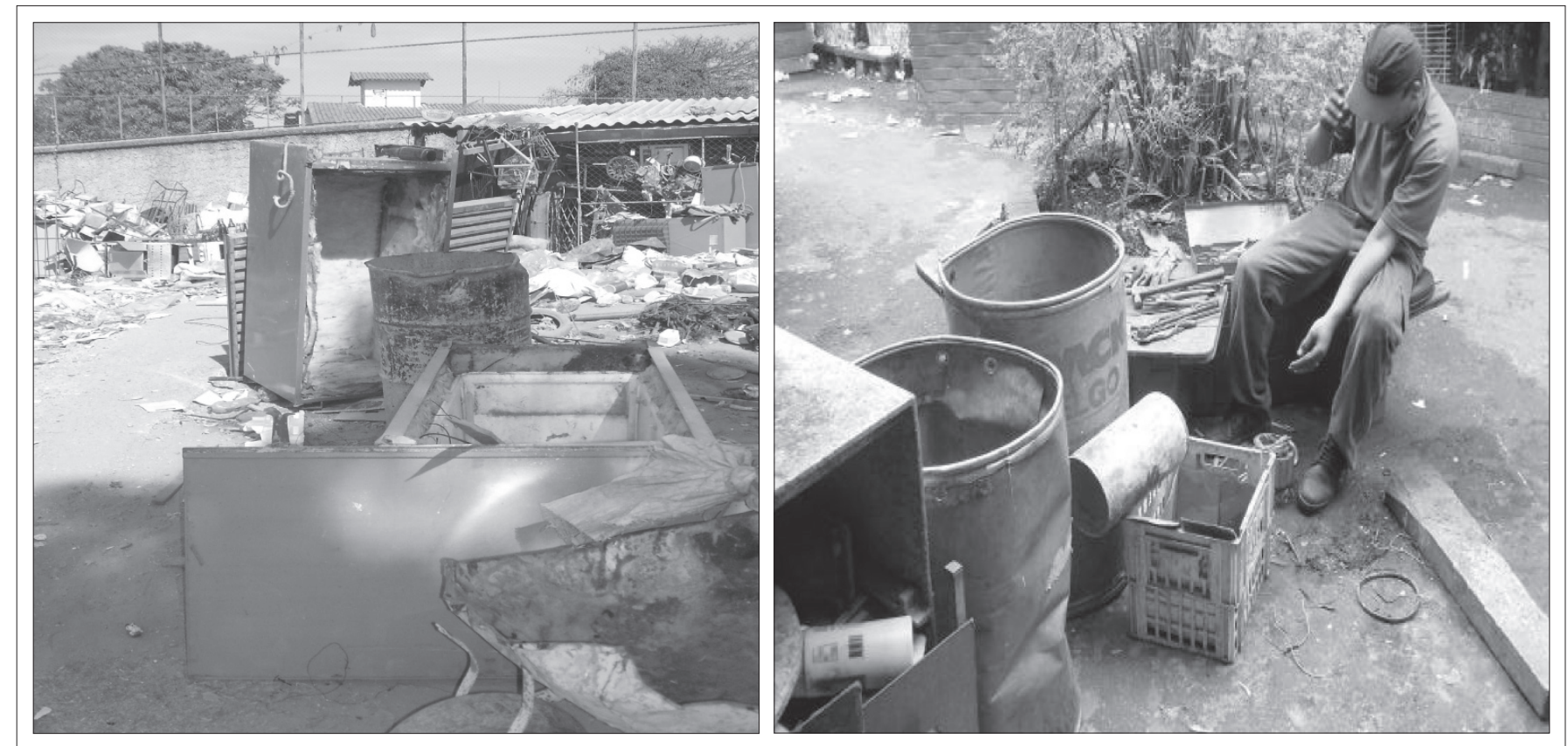

Figura 3 - Resíduo eletrônico e desmonte de motor elétrico para recuperação do cobre em sucateiros

Foram identificados no município de Belo Horizonte dois centros de inclusão digital, o Centro de Recondicionamento de Computadores de Belo Horizonte (CRC) e o Comitê para Democratização da Informática (CDI).

No CRC, as "máquinas" chegam por meio de doações de órgãos do governo federal, estadual e municipal, pessoas físicas, empresas privadas, universidades, entre outros. Ao recebê-la, é feita uma triagem para testar as máquinas a fim de verificar as condições de uso. Máquinas muito antigas já são encaminhadas para reciclagem e as mais novas seguem para o processo de manutenção.
Segundo o entrevistado, os resíduos gerados no início do projeto tinham o seguinte destino após o recondicionamento dos computadores: os CRTs eram mandados para uma empresa situada no Estado de São Paulo, onde tal empresa os exportava para o Japão; as carcaças dos gabinetes, que são predominantemente de ferro, eram doadas para catadores da região. No entanto, esse fluxo mudou e, no período da presente pesquisa, o CRC-BH estava armazenando todos os resíduos oriundos dos equipamentos de informática no galpão da Associação Municipal de Assistência Social (Amas), aguardando informações dos órgãos competentes sobre a destinação correta dos resíduos. 
O Comitê para Democratização da Informática de Belo Horizonte (CDI-BH), é uma organização não governamental, sem fins lucrativos, que tem como objetivo promover a inclusão digital visando à inclusão social. Na entrevista com o responsável, apurou-se que a unidade recebe todo o tipo de EEE, como televisores, aparelhos de som, telefones celulares, telefones fixos, aparelhos de fax, entre outros. Feita a triagem, constatou-se o seu potencial de reaproveitamento. Quando questionado sobre o que fazia com os resíduos eletrônicos, o entrevistado relatou que há uma parceria entre o CDI-BH e um sucateiro da região, funcionando da seguinte maneira: como o CDI-BH não tem como retirar determinadas doações, pois não tem veículo próprio, o "sucateiro" retira essa mercadoria do doador e leva até o CDI, onde é feita a triagem. O material não utilizado, bem como as peças que não são reparáveis, é vendido a preço simbólico ao sucateiro. O sucateiro informou que separa os metais da fiação, "descasca" o mouse para retirar o alumínio e tritura o plástico, sendo o material revendido a outras empresas. Sobre o que o sucateiro fazia com os CRTs, o entrevistado não soube responder com precisão, informou que "acha" que são quebrados para retirada do material de valor e o restante vai para o aterro.

Com a finalidade de complementar as informações sobre descaracterização de equipamentos foram identificadas, no Estado de São Paulo, nove empresas de descaracterização de resíduos sendo que somente duas permitiram visita, definindo-se, assim, a amostragem. No Estado de Minas Gerais, depois de exaustiva pesquisa em diversas fontes, não foi encontrada nenhuma empresa que oferecesse esse serviço. Nesta pesquisa, as empresas serão tratadas por R-1 e R-2.

A empresa R-1 atua na área de gestão ambiental há, aproximadamente, 10 anos, mas somente em 2007 iniciou suas atividades na área de gestão de resíduos eletrônicos. As instalações consistem em um galpão industrial e o setor administrativo. O galpão industrial possui como infraestrutura mesas para separação manual dos componentes, áreas de armazenamento, um maquinário para retirada de resíduos de tôner de cartuchos de impressoras e tesoura para corte de metal e placas de circuito impresso. Conforme informações do respondente, a empresa trabalha com todos os tipos de sucata eletrônica, de pequenos eletrodomésticos a equipamentos médicos, porém, a pesquisadora observou a predominância de sucata de computadores.

A quantidade de material recebido é de aproximadamente duas toneladas por mês. O fluxo do material se estabelece nos seguintes procedimentos: mediante solicitação do cliente, a R-1 envia um representante ao local para fazer a análise do produto/lote. Esse material pode ser retirado no cliente ou entregue diretamente à R-1. Quando esse material chega à R-1 ocorre a conferência da documentação e seu registro fotográfico, sendo então desmontados e os itens separados de acordo com o tipo (plástico, ferro, alumínio, entre outros), retirandose a marca, modelo e nome fantasia. São separadas as peças consideradas tóxicas como baterias e pilhas e dadas a elas a destinação específica, no caso, aterro industrial licenciado. Depois de triturados, os materiais são encaminhados aos parceiros/sucateiros.

Os plásticos são recolocados no mercado em torno de 96\%, os materiais ferrosos e não ferrosos em sua totalidade, bem como o papelão e o isopor usados nas embalagens. Materiais como fibra de vidro e plásticos contendo retardantes de chama são destinados ao aterro industrial por serem considerados resíduos classe I. Os CRTs são encaminhados para uma empresa de gerenciamento de resíduos, localizada em Paulínia, São Paulo, após juntarem 50 peças, o que leva aproximadamente três meses. As placas de circuito impresso são enviadas a uma empresa na Alemanha, pois o Brasil não possui tecnologia para sua reciclagem.

A Empresa R-2 é uma empresa nacional especializada na desmontagem, descaracterização e destruição de produtos inservíveis ou fora de linha, bem como na destinação final dos resíduos de diversas naturezas. O volume mensal processado informado fica entre 40 e 50 toneladas somente na área de REEE, uma vez que a empresa trabalha com diversos tipos de resíduos pós-consumo. O fluxo do material se estabelece nos seguintes procedimentos: retirada do material no cliente; controle de peso na entrada do caminhão lacrado; descarregamento; registro fotográfico do lote; desmontagem; caracterização por tipo de material; descaracterização/trituração, enfardamento e pesagem. Dependendo do material, ele deve ser prensado.

Todos os materiais processados são vendidos para empresas que comercializam materiais recicláveis no intuito de centralização, para posteriormente serem encaminhados para reciclagem. Esse fluxo é necessário para que ocorra mais aproveitamento do produto, como comentado pelo entrevistado: com esse tipo de esquema até mesmo os plásticos com retardantes de chama conseguem ser reaproveitados, pois são misturados aos demais na proporção de $10 \%$. As placas de circuito impresso são enviadas para reciclagem no exterior. Os materiais que não possuem reciclagem ou não possuem compradores, como os CRTs, são enviados ao aterro industrial ou incinerados, sendo o cliente responsável pela escolha do processo.

Para identificar o fluxo dos REEEs em locais de disposição final, visitou-se o aterro sanitário de Belo Horizonte, Central de Tratamento de Resíduos Sólidos da BR-040 (CTRS-BH), único local de disposição final dos resíduos sólidos do município. O responsável pelo aterro informou que recebem partes internas de geladeiras e fogões, embora seja bem raro, e que ocorre grande demanda quando a prefeitura faz campanhas contra a dengue e as pessoas "limpam" seus terrenos, e que são identificados na frente de trabalho telefones e pequenos eletrodomésticos que são compactados junto com os demais resíduos.

$\mathrm{Na}$ Feam, Semad e CMRR foi constatado que a preocupação dos órgãos frente aos REEEs é recente e que estavam trabalhando em um projeto para recondicionamento de computadores, que foi lançado em agosto de 2008. Quando questionada se já houve demanda sobre esse tema junto ao órgão, a responsável informou que a mídia (redes de televisão e jornais) tem procurado saber a posição do órgão 
e somente uma empresa os procurou para saber que destino dar aos seus EEEs obsoletos, os quais foram recomendados que direcionassem para empresas no Estado de São Paulo, a qual a entrevistada havia visitado.

Em julho de 2008, a assessoria de comunicação da SLU-BH informou não possuir nenhum trabalho referente a esse tipo de resíduo e que, quando as pessoas ligam para saber que destino dar aos computadores obsoletos a SLU fornece o endereço do Centro de Recondicionamento de Computadores (CRC).

\section{Conclusão}

Um dos fatores do sucesso dos sistemas de gerenciamento de REEE em países desenvolvidos se deve ao fato de a legislação vigente adotar o princípio da responsabilidade estendida do produtor, o que leva o fabricante a desenvolver equipamentos a partir do conceito de ecodesign, investir em pesquisas de reciclagem dos materiais e adotar a logística reversa.

No Brasil, foram encontrados alguns sistemas pontuais de gestão formal para computadores e aparelhos de celular, bem como seus acessórios. Os demais aparelhos eletrônicos são descartados junto ao lixo domiciliar. As empresas fornecedoras de telefones celulares no Brasil possuem canais reversos estruturados para o retorno da bateria, do aparelho celular e seus acessórios, por meio das lojas de assistência técnica e pontos de venda. Nesses locais são instaladas urnas receptoras para celulares e periféricos pós-consumo, que após recolhidos são encaminhados para descaracterização e posterior reciclagem das peças. No entanto a divulgação desse sistema de recolhimento para os usuários ainda é deficiente.

As iniciativas de gestão para os computadores pessoais são pontuais e partem de organizações não governamentais que incluem a capacitação de jovens com vulnerabilidade social em projetos de recondicionamento das máquinas para fomento da inclusão digital, no entanto, os resíduos eletrônicos gerados nesses projetos não possuem destinos ambientalmente adequados.

No estado de São Paulo existem empresas de gestão de resíduos e entre seus processos está inserida a descaracterização de equipamentos eletrônicos. Seus clientes são fabricantes de equipamentos eletrônicos ou empresas que possuem certificação ambiental e necessitam dar um destino ambientalmente correto para seus resíduos. As empresas visitadas não recebem esse material de pontos de coleta seletiva dos municípios ou de pequenos geradores. Não foi localizada nenhuma empresa de gestão de resíduos eletrônicos no município de Belo Horizonte e/ou no Estado de Minas Gerais, o que caracteriza um campo para implantação desse setor empresarial no Estado.

A estimativa de geração calculada mostra a necessidade de se programar um sistema de gerenciamento de REEE no município de Belo Horizonte. Os resultados indicaram que o principal destino, dados pelos consumidores particulares, dos aparelhos celulares, TV, PC e geladeira, finda à primeira vida útil, é a doação (34, 44, 36 e 48\%, respectivamente), o que não implica destinação adequada desses materiais, uma vez que esta alternativa pode ser interpretada como uma maneira de transferir o problema de gestão para o outro usuário. As visitas às cooperativas de catadores de materiais recicláveis, às empresas que comercializam sucatas e no local de disposição final de resíduos comprovaram que esse material existe em grande quantidade e o gerenciamento ambientalmente adequado é inexistente.

Os impactos ambientais negativos decorrentes da disposição inadequada dos resíduos de equipamentos elétricos e eletrônicos, bem como a perda econômica, proveniente da não valorização dos materiais recicláveis presentes na sua composição, são questões vitais e que merecem especial atenção da sociedade civil, dos órgãos ambientais, do governo, dos acadêmicos e da iniciativa privada.

A infraestrutura de coleta específica desses resíduos é inexistente no município. As alternativas existentes, até o término da presente pesquisa, para o descarte dos equipamentos elétricos e eletrônicos pós-consumo são: a disposição para coleta junto aos resíduos domiciliares; as operações especiais dos serviços de limpeza urbana como os bota-fora ou a entrega nas unidades de recebimento de pequenos volumes, nos quais são dispostos os eletrodomésticos de grande porte, no entanto, o destino final será o aterro sanitário; a doação direta a catadores que destinam os materiais às cooperativas de materiais recicláveis ou a disposição junto aos outros materiais recicláveis em pontos de entrega voluntária.

\section{Referências}

AGÊNCIA NACIONAL DE TELECOMUNICAÇÕES (ANATEL). Quantidade de Acessos/Plano de Serviço/Unidade de Federação. Disponível em: $\quad$ http://sistemas.anatel.gov.br/SMP/Administracao/Consulta/ AcessosPrePosUF/tela.asp > . Acesso em: 26 fev.2011.

BRASIL. Lei 12.305, de 02 de agosto de 2010. Institui a Política Nacional de Resíduos Sólidos. Diário Oficial [da] República Federativa do Brasil, Poder Executivo, Brasília, DF, 3 ago. 2010. Seção 1, p. 3.
Atlas do Desenvolvimento Humano no Brasil. Programa das Nações Unidas para o Desenvolvimento. 1991 e 2000.

ENVIRONMENTAL PROTECTION AGENCY (EPA). Electronic waste management in the United States, Approach 1 e 2, Estados Unidos. 2007.

FRANCO, R. G. F. Protocolo de referência para gestão de resíduos de equipamentos elétricos e eletrônicos domésticos para o município de 
Belo Horizonte. Dissertação - Universidade Federal de Minas Gerais, Programa de pós-graduação em Saneamento, Meio Ambiente e Recursos Hídricos, 162p. 2008.

FUNDAÇÃO GETÚLIO VARGAS, Escola de Administração de empresas de São Paulo (FGV/EAESP). 18ª. Pesquisa Anual, 2007 realizada por FGVEAESP-CIA - Centro de Tecnologia de Informação Aplicada da Escola de Administração de Empresas de São Paulo da Fundação Getulio Vargas, coordenada por Prof. Fernando S. Meirelles. Disponível em:<http:// www.eaesp.fgvsp.br/subportais/Interna/Relacionad/FGV2007TI.pdf > . Acesso em: 19 de fev. 2008.

INSTITUTO BRASILEIRO DE GEOGRAFIA E ESTATÍSTICA (IBGE). Pesquisa Nacional por Amostra de Domicílios - PNAD- 2006. Rio de Janeiro: IBGE, 2006.

KANG, H.Y.; SHOENUNG J.M. Electronic waste recycling: A review of U.S. infrastructure and technology options. Resources Conservation \& Recycling, Elsevier, v. 45, p. 368-400, 2005.

LIM, S.R.; SCHOENUNG, J.M. Toxicity potentials from waste cellular phones, and a waste management policy integrating consumer, corporate, and government responsibilities. Waste Management. v. 30, p. $1653-1660,2010$

LIU, X.; TANAKA, M.; MATSUI, Y. Electrical and eletronic Waste Management in china: progress and barriers to overcome. Waste Management Research, v. 24, p. 92-101, 2006.

PARLAMENTO EUROPEU. RoHs. Directiva 2002/95/CE do Parlamento Europeu e do Conselho de 27 de janeiro de 2003: relativa à restrição do uso de determinadas substâncias perigosas em equipamentos eléctricos e electrónicos, 2003.

RIS International, Five Winds International and Electro-Federation Canada. Baseline Study of End-of-Life Electrical and electronic in Canada, Relatório preparado para Environment Canadá, 2003.

RODRIGUES, A.C. Impactos socioambientais dos resíduos de equipamentos elétricos e eletrônicos: estudo da cadeia pós-consumo no Brasil. Dissertação - Universidade Metodista de Piracicaba, Faculdade de Engenharia, Arquitetura e Urbanismo, Programa de Pós-Graduação em Engenharia de Produção. São Paulo, 2007.

ROMAN, G. Diagnóstico sobre la generación de basura electrónica. Instituto Politécnico Nacional México, Centro Interdisciplinario de Investigaciones y Estudios sobre Medio Ambiente y Desarrollo México D.F., 2007

SAMARA, B.S.; BARROS, J.C. Pesquisa de Marketing: conceitos e metodologia. 3. ed., São Paulo: Pearson Prentice Hall, 2002.

WANG, F.; LEUNG, A.O.W.; WU, S.C.; Yang, M.S., et al. Chemical and ecotoxicological analyses of sediments and elutriates of contaminated rivers due to e-waste recycling activities using a diverse battery of bioassays. Environmental Pollution, v. 157, n. 7, p. 2082-2090, 2009

XING, G.H.; CHAN, J.K.Y.; LEUNG, A.O.W.; Wu, S.C. et al. Environmental Impact and human exposure to PCB's in Guiyu and electronic waste recycling site in China. Environmental International, v. 35, p. 76-82, 2009. 